\title{
The interaction of glucagon and pentagastrin on the lower oesophageal sphincter in man and dog
}

\author{
H. M. JENNEWEIN, F. WALDECK, R. SIEWERT, F. WEISER, AND R. THIMM \\ From the Department of Pharmacology, C.H. Boehringer Sohn, Ingelheim, and the Surgical Clinic, \\ Göttingen University, West Germany
}

SUMMARY The effect of glucagon on the pressure inside the lower oesophageal sphincter in conscious human subjects and anaesthetized dogs was investigated using the continuous withdrawal method. Glucagon causes a decrease in sphincteric resting pressure in both man and dog and antagonizes the pentagastrin-induced pressure increase of the lower oesophageal sphincter. In experiments on isolated muscle strips of the lower oesophageal sphincter of dogs glucagon decreases the tension and antagonizes the increase in tension induced by pentagastrin. The elevated pressure in patients suffering from achalasia is significantly reduced by glucagon.

As a result of the investigations of Giles, Mason, Humphries, and Clark (1969), Castell and Harris (1970), and Cohen and Lipshutz (1971) the physiological significance of gastrin in the regulation of lower oesophageal sphincter strength is well documented. Furthermore Cohen and Lipshutz (1971) showed that secretin acts as a gastrin antagonist on the lower oesophageal sphincter. It is known that there is a chemical similarity between secretin and glucagon. Both of these hormones inhibit gastrointestinal motility (Dotevall and Kock, 1963; Hubel, 1972), and in addition, glucagon suppresses gastrin as well as histamine-stimulated gastric acid secretion (Hubel, 1972; Wilson, Ginsberg, Levine, and Washington, 1972). Because of these aspects we have been interested in the action of glucagon and in any possible gastrin antagonism of this hormone on the lower oesophageal sphincter.

\section{Methods}

The investigations were performed in 24 conscious human volunteers of both sexes with ages ranging from 20 to 25 years and in four male and six female patients ( 40 to 65 years of age) suffering from achalasia. In order to measure the maximum pressure inside the lower oesophageal sphincter before and after injection of glucagon the continuous withdrawal method was used (Waldeck, 1972; Waldeck, Jennewein, and Siewert, 1973). In these tests a catheter with four lateral holes, diameter of 4.5

Received for publication 15 August 1973. $\mathrm{mm}$, and situated at the same level above its sealed end, was used. After inserting the catheter into the stomach it was withdrawn in the state of expiration at a constant speed $(6 \mathrm{~mm} / \mathrm{sec})$ from the stomach through the lower oesophageal sphincter into the oesophagus during continuous perfusion $(5 \mathrm{ml} / \mathrm{min})$. The pressure changes during withdrawal were continuously recorded on a Helcoscriptor. The pressure profiles obtained reflect the lowest pressure at one of the four holes at any given moment. From these profiles the maximum pressure was taken for further evaluation as this is the most important value in respect of reflux. This maximum pressure is always given in the text. Furthermore the common manometric technique with three perfused open-sided catheters was applied to study patients with achalasia.

In animal experiments beagle and mongrel dogs of both sexes with a body weight of between 10 and $17 \mathrm{~kg}$ were used. The animals were lightly anaesthetized with chloralose urethane and then curarized (Gallamine $1 \mathrm{mg} / \mathrm{kg}$ ). The continuous withdrawal method was used in these experiments in an identical manner as that described above.

In 12 anaesthetized dogs circular muscle strips were dissected from the lower oesophageal sphincter and suspended in an oxygen-bubbled tyrode bath. The tension of the strips was measured by means of an isometric transducer (Grass FT-03c) and was registered on a Grass polygraph. After an equilibration period of $40 \mathrm{~min}$ during which the tyrode solution was twice replaced, either pentagastrin (J.C.J. 50, 123) was instilled in such amounts that 
the bath concentration was between $10^{-11}$ and $10^{-6} \mathrm{~g} / \mathrm{ml}$ or glucagon was added to achieve a concentration of $10^{-8}$ or $10^{-5} \mathrm{~g} / \mathrm{ml}$. In further tests the pentagastrin response of muscle strips was tested following the administration of glucagon.

For statistical evaluation of the results the Bartlett test, t test, and Dunnett test (1964) were used.

\section{Results}

SINGLE INJECTIONS OF GLUCAGON

Figure 1 demonstrates that single intravenous injections of glucagon cause a decrease in sphincteric pressure in both man and dog. The doses of $60 \mu \mathrm{g} / \mathrm{kg}$ in man and $100 \mu \mathrm{g} / \mathrm{kg}$ in dogs yield a maximum decrease in sphincteric tone, which is more than $50 \%$ in man and nearly $100 \%$ in the dog. The effect of single injections of glucagon lasts for about

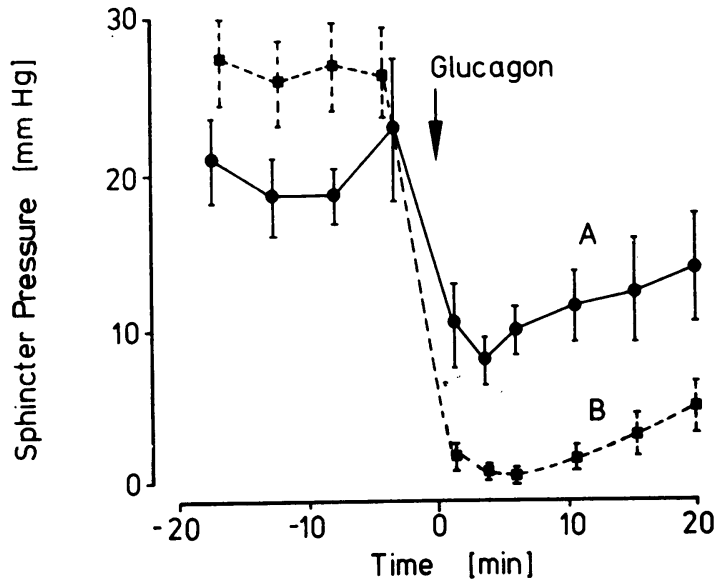

Fig 1 Effect of single injections of glucagon on the pressure in the lower oesophageal sphincter in man (60 $\mu \mathrm{g} / \mathrm{kg}$ intravenously, curve A) and dog (100 $\mu \mathrm{g} / \mathrm{kg}$ intravenously, curve $B) ; n=10, \bar{x} \pm S E$.

30 min in both man and dog. As shown by the dose response curve of glucagon in dogs (fig 2) even a dose as low as $1 \mu \mathrm{g} / \mathrm{kg}$ shows a distinct decrease in sphincteric pressure.

\section{CONTINUOUS INTRAVENOUS INFUSION OF GLUCAGON}

A continuous intravenous infusion of glucagon also causes a reduction in sphincteric tone. As shown in fig 3 a glucagon infusion of $0.5 \mathrm{mg} / \mathrm{kg}-\mathrm{hr}$ reduces sphincteric pressure in dogs almost completely. Since the blood sugar level increases as a result of this infusion, similar experiments were performed injecting glucose. Neither single injections $(1 \mathrm{ml} / \mathrm{kg})$ nor continuous intravenous infusion $(10 \mathrm{ml} / \mathrm{kg}-\mathrm{hr})$ of $10 \%$ glucose showed any effect on sphincteric pressure in dogs.

\section{PENTAGASTRIN ANTAGONISM}

In the upper part of fig 4 the typical bell-shaped dose response curve of pentagastrin on the pressure of the lower oesophageal sphincter in dogs is given.

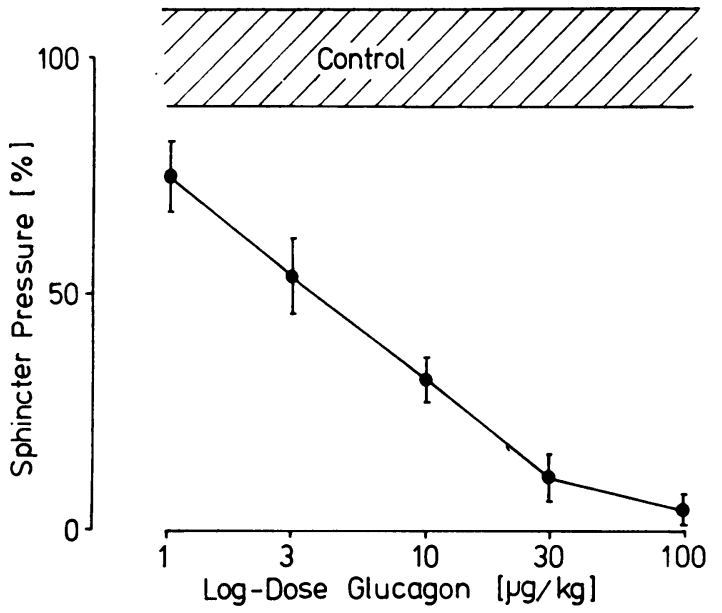

Fig 2 Dose response curve of single intravenous injections of glucagon on the pressure in the lower oesophageal sphincter in dogs; $n=10, \bar{x} \pm S E$.

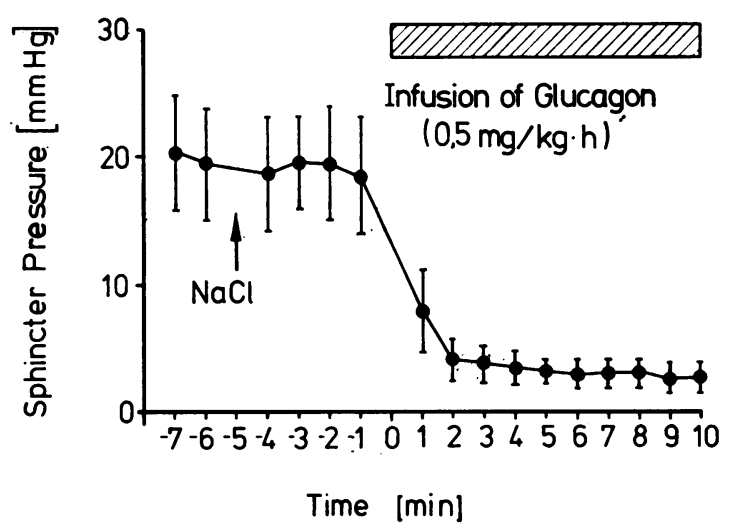

Fig 3 Effects of continuous intravenous infusions of glucagon on the pressure in the lower oesophageal sphincter in dogs; $n=10, \bar{x} \pm S E$.

The two lower diagrams in fig 4 demonstrate that there is a flattening in the dose response curve of pentagastrin, which is due to the glucagon infusion. It is to be seen that the degree of flattening depends on the dose of glucagon administered. 


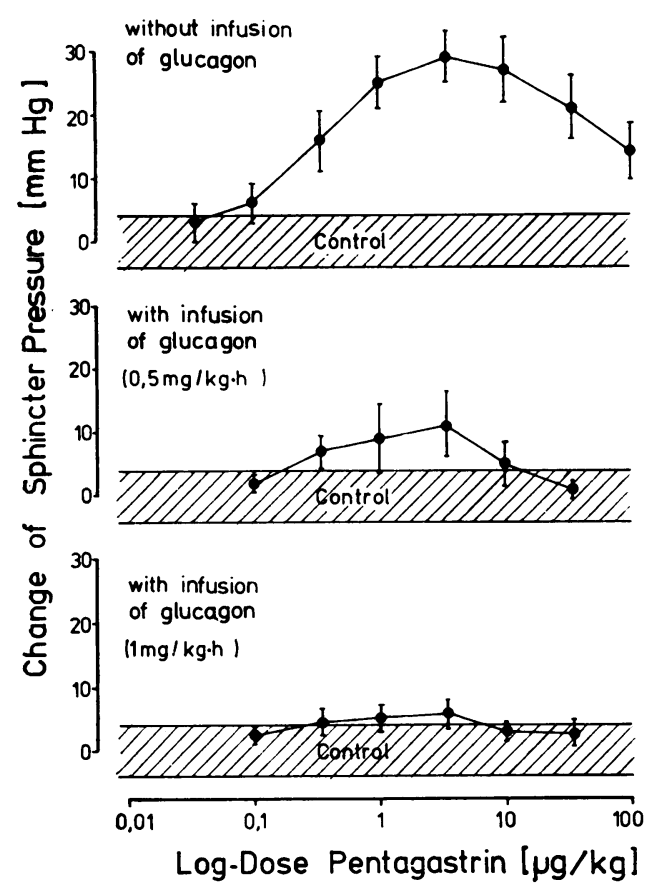

Fig 4 Effects of continuous intravenous infusions of glucagon on the dose response curve of pentagastrin on the pressure inside the lower oesophageal sphincter in dogs; $n=10, \bar{x} \pm S E$.

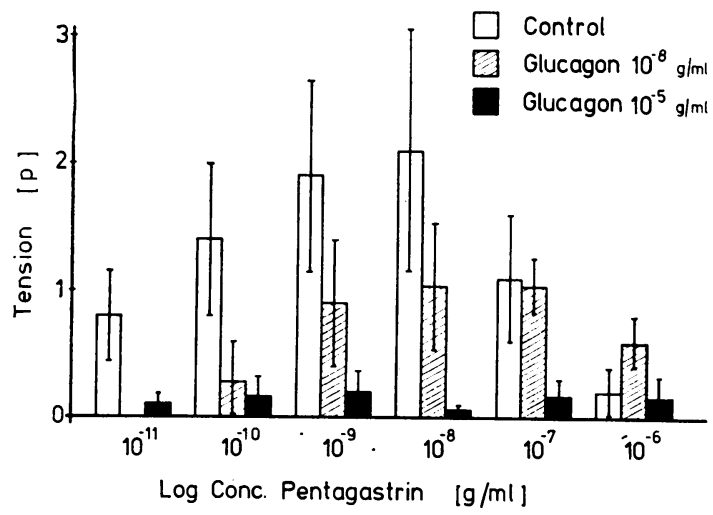

Fig 5 Effects of two concentrations of glucagon on the pentagastrin response on isolated muscle strips from the lower oesophageal sphincter of dogs; $n=6, \bar{x} \pm S E$.
In four pilot tests in man a glucagon infusion (750 $\mu \mathrm{g} / \mathrm{kg}$-hr) resulted in a $40 \%$ decrease in sphincteric pressure. This low pressure level was not altered by single injections of pentagastrin $(0.6$ $\mu \mathrm{g} / \mathrm{kg}$ ). However, it must be mentioned that the administration of pentagastrin during glucagon infusion elicits nausea and vomiting.

EXPERIMENTS ON ISOLATED MUSCLE STRIPS In 12 experiments on isolated muscle strips from the lower oesophageal sphincter of dogs the tension of the strips was regularly reduced by applying glucagon in the concentrations of $10^{-8}$ and $10^{-5} \mathrm{~g} / \mathrm{ml}$. The decrease in tone was $18 \pm 9 \%(\bar{x} \pm \mathrm{SE})$ after the administration of $10^{-8} \mathrm{~g} / \mathrm{ml}$ and $84 \pm 23 \%$ after $10^{-5} \mathrm{~g} / \mathrm{ml}$. In fig 5 the white columns reflect a doseeffect curve of pentagastrin on the tension of isolated sphincter strips. They show that a maximum increase in tone is achieved by concentrations of $10^{-9}$ to $10^{-8}$ $\mathrm{g} / \mathrm{ml}$. The effect of higher concentrations is considerably smaller.

After establishing a glucagon concentration in the organ bath of $10^{-8} \mathrm{~g} / \mathrm{ml}$, the consecutive administration of pentagastrin in various doses appears to result in a considerably reduced increase in tone (dashed columns in fig 5). In comparison to the controls, only the difference at $10^{-10} \mathrm{~g} / \mathrm{ml}$ pentagastrin is statistically significant $(\mathrm{P}<0.05)$. According to the black columns in fig 5 , pretreating the muscle strips with $10^{-5} \mathrm{~g} / \mathrm{ml}$ glucagon significantly inhibits the pentagastrin response $(P<0.001)$ over the range of $10^{-11}$ to $10^{-7} \mathrm{~g} / \mathrm{ml}$.

\section{GLUCAGON IN ACHALASIA}

The effect of glucagon on sphincteric tone was investigated in four male and six female patients, in whom the diagnosis of achalasia was confirmed clinically and cineradiographically. The resting pressure in the lower oesophageal sphincter of these patients was $35 \pm 3.9 \mathrm{~mm} \mathrm{Hg}(\bar{x} \pm \mathrm{SE})$. This value is significantly $(P<0.01)$ higher than the resting pressure of 20 healthy subjects, which is $19 \pm 2.5 \mathrm{~mm} \mathrm{Hg}(\bar{x} \pm \mathrm{SE})$. Intravenous injection of $60 \mu \mathrm{g} / \mathrm{kg}$ glucagon decreases the elevated resting pressure of patients suffering from achalasia significantly $(P<0.002)$ to a value of $17 \pm 2.3 \mathrm{~mm} \mathrm{Hg}$ $(\bar{x} \pm \mathrm{SE})$ three minutes after administration. This effect lasts for about 15 minutes.

\section{Discussion}

The results demonstrate that glucagon decreases the maximum pressure inside the lower oesophageal sphincter in man and dog, when given as single injections or as continuous infusions. Furthermore, we found that the response of the lower oesophageal 
sphincter to pentagastrin is inhibited during infusion of glucagon. Since similar observations were made on isolated muscle strips of the lower oesophageal sphincter in dogs there is good evidence that glucagon is directly affecting it. In addition one has to keep in mind that the effect of glucagon in vivo could also in part be due to the known effect of glucagon suppressing the release of gastrin (Becker, Reeder, Lerman, and Thompson, 1972). It has recently been shown that serum gastrin in normal subjects decreases significantly after rapid intravenous injection of $1 \mathrm{mg}$ of glucagon (Hansky, Soveny, and Korman, 1973). Similar results have been obtained after intravenous infusion of glucagon $(30 \mu \mathrm{g} / \mathrm{kgh})$ in normal persons, patients with duodenal ulcer, and in dogs before and after a standard meal (Becker, Reeder, and Thompson, 1973). In comparison to secretin, which shifts the dose response curve of gastrin in man (Cohen and Lipshutz, 1971) and of pentagastrin in dogs (Jennewein, Waldeck, and Prahl, 1972) to the right, glucagon causes a flattening of the pentagastrin dose response curve without any lateral shift. In contrast to secretin these results indicate that glucagon might inhibit the pentagastrin response of the lower oesophageal sphincter in a non-competitive way. Therefore, a chemical inhibition of gastrin before reaching the receptor site, as was discussed for secretin (Cohen, and Lipshutz, 1971), seems improbable for glucagon. The finding that glucagon reduces the sensitivity of the lower oesophageal sphincter to pentagastrin could contribute to the glucagon-induced decrease in sphincteric pressure in patients suffering from achalasia, who were shown to be hypersensitive to gastrin (Cohen, Lipshutz, and Hughes, 1971).

Until now it has not been clear whether the effect of glucagon on the lower oesophageal sphincter is a physiological one. The glucagon doses needed to achieve an effect on the lower oesophageal sphincter are relatively high and an effect of endogenously released glucagon on the lower oesophageal sphincter has not yet been demonstrated. It is known, however, that cholecystokinin (CCK) is one of the most potent substances in releasing endogenous glucagon (Unger, Ketterer, Dupré, and Eisentraut, 1967). When CCK is given intravenously in a dose of 3 Ivy $\mathrm{U} / \mathrm{kg}$ the sphincteric pressure is reduced in man (Giles and Roszkowski, 1972) and dog (Jennewein et al, 1972) although there is no clear dose response curve. The effect of CCK could either be a direct relaxation of the lower oesophageal sphincter or a gastrin antagonistic one, in which glucagon might be involved. Unfortunately the CCK available to us (Karolinska-Institute Sweden) is impure and extensive studies with purer preparations will be necessary to elucidate this aspect further.

Our sincere thanks are due to Mr Kurt Paulus for his valuable technical assistance.

\section{References}

Becker, H. D., Reeder, D. D., Lerman, M., and Thompson, J. C. (1972). Effect of glucagon on circulating gastrin. (Abstr.) Gastroenterology, 62, 720.

Becker, H. D., Reeder, D. D., and Thompson, J. C. (1973). Effect of glucagon on circulating gastrin. Gastroenterology, 65, 28-35.

Castell, D. O., and Harris, L. D. (1970). Hormonal control of gastroesophageal sphincter strength. New Engl.J. Med., 282, 886-889.

Cohen, S., and Lipshutz, W. (1971). Hormonal regulation of human lower esophageal sphincter competence, interaction of gastrin and secretin. J. clin. Invest., 50, 449-454.

Cohen, S., Lipshutz, W., and Hughes, W. (1971). Role of gastrin supersensitivity in the pathogenesis of lower esophageal sphincter hypertension in achalasia. J. clin. Invest., 50, 12411247.

Dotevall, G., and Kock, N. G. (1963). The effect of glucagon on intestinal motility in man. Gastroenterology, 45, 364-367.

Dunnett, C. W. (1964). New tables for multiple comparisons with a control. Biometrics, 20, 482-491.

Giles, G. R., Mason, M. C., Humphries, C., and Clark, C. G. (1969). Action of gastrin on the lower oesophageal sphincter in man. Gut, 10, 730-734.

Giles, G. R., and Roszkowski, A. (1972). Der Einfluss von Hormonen auf den unteren Osophagussphinkter beim Menschen. Leber, Magen, Darm, 2, 20-22.

Hansky, J., Soveny, C., and Korman, M. G. (1973). The effect of glucagon on serum gastrin. I Studies in normal subjects. Gut, 14, 457-461.

Hubel, K. A. (1972). Secretin: a long progress note. Gastroenterology, 62, 318-341.

Jennewein, H. M., Waldeck, F., and Prahl, K. (1972). Zur Beeinflussung des unteren Osophagussphinkters durch gastrointestinale Hormone beim Hund. Leber, Magen, Darm, 2 , 17-19.

Unger, R. H., Ketterer, H., Dupré, J., and Eisentraut, A. M. (1967). The effects of secretin, pancreozymin, and gastrin on insulin and glucagon secretion in anesthetized dogs. J. clin. Invest., 46 , 630-645.

Waldeck, F. (1972). A new procedure for functional analysis of the lower esophageal sphincter (LES). Pflügers Arch. ges. Physiol., 335, 74-84.

Waldeck, F., Jennewein, H. M., and Siewert, R. (1973). The continuous withdrawal method for the quantitative analysis of the lower oesophageal sphincter (LOS) in humans. Europ. $J$. clin. Invest., III, 331-337.

Wilson, D. E., Ginsberg, B., Levine, R. A., and Washington, A. (1972). Effect of gl Icagon on histamine- and pentagastrin-stimulated canine gastric acid secretion and mucosal blood flow. Gastroenterology, 63, 45-50. 